\title{
EL CULTIVO DE LAS HUMANIDADES Y LAS EMOCIONES: REFLEXIONES EN TORNO A LA EDUCACIÓN MORAL Y POLÍTICA
}

\author{
MARTA GIL \\ Universidad de Valencia
}

\begin{abstract}
RESUMEN: En el presente artículo se expone una reflexión sobre la deriva actual de la educación a partir del pensamiento de Martha Nussbaum. Sometida a los imperativos del crecimiento económico, la educación es vista como una mera herramienta para triunfar en el mercado laboral, y las artes y las humanidades se están viendo cada vez más marginadas en los programas de estudios. Hablaremos del cultivo de la imaginación empática y de la compasión como mecanismos que nos ayudan a comprender a personas distintas de nosotros, y a preocuparnos por ellos. Veremos cómo el papel de estas emociones resulta relevante para impulsarnos a ayudar a aquél que se encuentra en una situación de vulnerabilidad o sufrimiento. Por ello, defenderemos que el cultivo de estas emociones puede forjar una mejor agencia moral, y también mejorar nuestra faceta como ciudadanos, haciéndonos más sensibles a las necesidades de los demás e inclinando nuestras decisiones políticas hacia la cooperación y la solidaridad.
\end{abstract}

PALABRAS CLAVE: educación moral, educación política, imaginación empática, compasión, Martha Nussbaum, humanidades, democracia.

\section{The Cultivation of Humanities and Emotions. Reflections on Moral and Political Education}

\begin{abstract}
: the present paper involves a reflection on the current orientation that education is adopting based on Martha Nussbaum's thinking. Under the imperative of the economic growth, education is seen as a mere means to achieve success in the job market, and arts and humanities are being marginalized from study programs increasingly. We will talk about the cultivation of empathic imagination and compassion as mechanisms that help us to understand people that are different from us, and to acquire a concern for them. We will see why the role of these emotions might be relevant in order to prompt us to help whoever that finds himself in a vulnerability situation or suffering. This is why we will argue that the cultivation of these emotions may help us to develop a better moral agency, and also to enhance our condition as citizens, making us more sensitive towards other's necessities, and orienting our political decisions towards cooperation and solidarity.
\end{abstract}

KEY WORDS: moral education, political education, empathic imagination, compassion, Martha Nussbaum.

\section{El PaPel de la literatura EN El CUltivo de la imaginación}

Nussbaum insiste en la necesidad de cultivar la capacidad de imaginar las razones que mueven a actuar a personas que son distintas de nosotros, así como a preguntarnos por sus opciones y formas de vida, para que dejemos de verlas como «extraños que nos amenazan» y pasemos a verlas como «seres que 
comparten con nosotros muchos problemas y oportunidades» ${ }^{1}$. De lo que se trata, por tanto, es de lograr resquebrajar las diferencias de género, nacionalidad, religión o clase social que nos llevan a desatender y abandonar la preocupación por nuestra común humanidad. Las humanidades y las artes, como veremos, poseen un papel fundamental a la hora de lograr este cometido, puesto que «cultivan poderes de la imaginación que son esenciales para la construcción de la ciudadanía $»^{2}$. La democracia requiere de instituciones y procedimientos; pero éstas, a su vez, necesitan de una ciudadanía formada y preocupada por los asuntos públicos para mantenerse saludables.

Nuestra autora defiende que la literatura es un recurso especialmente valioso para dar forma a nuestras capacidades morales, y, en particular, para configurar nuestra capacidad para comprender a personas que son distintas de nosotros. Aunque otorga un lugar privilegiado a la literatura, también contempla la importancia de otras artes. Así, sostiene que la danza, la música, la pintura, la escultura y la arquitectura, todas «cultivan nuestras capacidades de juicio y sensibilidad $»^{3}$. El motivo que hace que la literatura tenga un lugar preeminente es que ésta hace que seamos capaces de aproximarnos a las vidas ajenas "con un interés mayor al de un turista casual» ${ }^{4}$, puesto que predispone nuestro entendimiento de un modo más receptivo a los problemas que acucian la vida de las personas, y hace que nos sintamos involucrados incluso con aquellos que parecen muy diferentes de nosotros mismos.

La lectura también ensancha nuestra capacidad para comprender cómo las circunstancias pueden impulsar o destruir los proyectos vitales de las personas. Proyectos que, con frecuencia, no difieren mucho de los nuestros propios, puesto que todos los seres humanos compartimos un conjunto básico de necesidades y expectativas vitales (relativas a cosas tales como la familia, la amistad, la salud, el hogar, etc.), por más que la plasmación particular que tomen unas y otras sea tan diversa como personas existen. Esta idea guarda estrecha relación con el ejercicio de una compasión racional que contribuya a hacernos ver las desgracias ajenas (como, por ejemplo, la pobreza o la falta de educación) no como un mal merecido, sino como un acontecimiento sobrevenido

1 Nussbaum, M., El cultivo de la humanidad. Una defensa clásica de la reforma en la educación liberal, Paidós, Barcelona, 2001, p. 121. La autora también ha tratado la relación entre literatura e imaginación empática en: Justicia poética: la imaginación literaria y la vida pública, Andrés Bello, Barcelona, 1997.

2 Ibíd., p. 121. Un estudio reciente en neurociencia y psicología de la New School for Social Research sugieren que la literatura (a diferencia de otros formatos como la ficción popular, la no ficción o a la ausencia total de lectura), mejora nuestra capacidad para elaborar «teorías de la mente», esto es, para comprender los estados mentales de los demás, habilidad que constituye un elemento básico de las relaciones humanas. Ver KidD, D. y Castano, E., «Reading Literary Fiction Improves Theory of Mind», Science 342, nº 6156 (2013), 377-80.

3 Nussbaum, El cultivo de la humanidad. Una defensa clásica de la reforma en la educación liberal, p. 122.

4 Ibid., p. 125. 
que también hubiera podido truncar nuestras propias vidas, o haberlas hecho muy distintas de lo que son ${ }^{5}$.

Por lo común, la compasión por el otro sufriente entendida como agitación interna, o como sentimiento, es un fenómeno que se dirige a otro individuo (o conjunto de individuos) en particular, y no a abstracciones. No obstante, el ejercicio de la compasión racional puede penetrar de tal modo en el carácter que no sólo se dirija a objetos particulares, sino que sea capaz de extenderse a otros objetos indefinidos (por ejemplo, los seres humanos en general). Esta capacidad de compadecer al otro en abstracto tendría cierta relevancia en nuestras deliberaciones como ciudadanos. ${ }^{6}$ La conciencia de que algunos males como la enfermedad, o la falta de empleo son algo que simplemente ocurre, y no algo que dependa únicamente de la diligencia o la dejadez individual, llevará a los ciudadanos a apoyar lo que Rawls denominó «el principio de diferencia», "que afirma que las desigualdades sociales y económicas relacionadas con cargos y posiciones tienen que estructurarse de tal modo que, cualquiera que sea el nivel de esas desigualdades, grandes o pequeñas, tienen que darse a mayor beneficio de los miembros menos aventajados de la sociedad ${ }^{7}$. La compasión, como reitera Nussbaum, entraña la comprensión de la propia vulnerabilidad ante la desgracia. Esta emoción hace que alberguemos «el pensamiento de que la persona que sufre podría ser yo» ${ }^{8}$. Este resorte psicológico nos persuade para que consideremos que es conveniente ayudar a aquél que se encuentra en una situación de necesidad: contemplar su desgracia nos hace pensar que podríamos ser nosotros los que nos encontráramos en su lugar, y que también desearíamos ser amparados en tal circunstancia. La compasión, por tanto, puede enriquecer nuestra faceta no ya como agentes morales, sino como ciudadanos, haciéndonos más sensibles a las necesidades de los demás e inclinando nuestras decisiones políticas hacia la cooperación y la solidaridad.

Nussbaum toma estas ideas para la educación moral principalmente de Rousseau, para quien una buena formación debe prepararnos para las vicisitudes de la fortuna. Y esto pasa por reconocer al otro, cualquiera que sea su condición: esclavo, enfermo, miembro de otra clase social, etc. La postura de Rousseau se recoge con claridad en el siguiente fragmento:

5 El monográfico más completo que conozco dedicado a la compasión es el libro de Arteta, A., La compasión, apología de una virtud bajo sospecha, Paidós, Barcelona, 1996. Joan Carles MÈLıch también analiza algunas cuestiones relativas al vínculo entre compasión, ética y vulnerabilidad en: Ética de la compasión, Herder, Barcelona, 2010. Y la propia NussBaum ha repetido en obras posteriores las intuiciones básicas acerca de la compasión que se encuentran en: "Compassion: The Basic Social Emotion», Social Philosophy and Policy 13, n". 1, 1996, p. 27-58.

6 Para una propuesta que une la ética del discurso con nuestras inclinaciones compasivas ver: CoRTinA, A., Ética de la razón cordial: educar en la ciudadanía en el siglo XXI, Nobel, Oviedo, 2007 y Justicia cordial, Trotta, Madrid, 2010.

7 Rawls, J., El Liberalismo político, Crítica, Barcelona, Crítica, 2004, p. 36.

8 Nussbaum, El cultivo de la humanidad. Una defensa clásica de la reforma en la educación liberal, p. 128. 
Dejémosle sentir las calamidades humanas (...) Inquietemos y asustemos su imaginación con los peligros que constantemente rodean a los seres humanos. Permitámosle contemplar todos estos abismos que los circundan y que escuche vuestra descripción, bien asido a ustedes por miedo a caer en sus profundidades ${ }^{9}$.

Rousseau considera importante educar a su pupilo en la conciencia de su propia vulnerabilidad y debilidad. Esto sería una condición necesaria para la compasión, para que el espectador comprenda que sus posibilidades son muy parecidas a las del otro sufriente.

Pese a esta visión de la literatura y del arte, Nussbaum reconoce que «la imaginación cívica no es la única función de la literatura», pero aun así, sostiene que ésta es «una función primordial» ${ }^{10}$. Así pues, no pasa por alto que la enseñanza moral que podamos extraer de una obra de arte no agota, ni mucho menos, su belleza. Está claro que las grandes obras destacan por su perfección formal y por su valor estético. No obstante, la autora considera que es imposible leer una tragedia de Sófocles o una novela de Dickens sin sentirse conmovido por las desventuras de sus protagonistas, y que, si éstas nos producen una perturbación del ánimo es porque somos capaces de contemplarlas a través de un elenco de ciertas categorías morales y políticas. La lectura se entrelaza de este modo con nuestras creencias relativas a los elementos que toda vida buena necesita para ser tal, y con aquellas creencias que tienen que ver con las dificultades que encaran las clases más desfavorecidas de la sociedad. Según Nussbaum, aquellos críticos pertenecientes a la «Nueva Crítica», que defendían una lectura exclusivamente formal de las obras literarias, excluyendo toda preocupación por las dimensiones históricas y sociales de las mismas, también llevaron a cabo un acto político: un acto inmovilista. A pesar de que la formación del agente moral y del ciudadano no es el principal objetivo del arte y la literatura, queda claro que ambos pueden ser empleados con esta finalidad.

Algo que es preciso valorar a la hora de tener en cuenta el papel que la literatura puede tener en la formación moral es que ésta, por sí misma, no siempre enseña cosas buenas. Una narración también puede estar del lado de la crueldad, si el lector no es capaz de realizar una reflexión apropiada debido a su juventud, a su falta de formación o a la carencia de ciertas categorías mentales necesarias para poder ser crítico. También puede ocurrir que, simplemente, las obras literarias reproduzcan o fomenten estereotipos y prejuicios. Simone de Beauvoir, por ejemplo, estudió la imagen que afamados escritores como Montherlant, D.H. Lawrence, Claudel, Breton o Stendhal proyectaron de la mujer como un ser ignorante, incapaz de captar la realidad y deficiente por naturaleza ${ }^{11}$.

Nuestra autora cree que la propia literatura también tiene un papel importante en el desarrollo del espíritu crítico. Así, la lectura no sólo debería

9 Pasaje del Emilio de Rousseau citado en: Ibíd., p. 130-131.

$10 \quad$ Ibid., p. 125.

11 Beauvoir, S. DE, El segundo sexo, Cátedra, Madrid, 2005. 
estimular la capacidad empática del lector, sino también su capacidad para cuestionar algunas prácticas y valores. Ahora bien, según lo que hemos argumentado, la literatura por sí sola no es suficiente para adquirir un sentido crítico. Precisamente por esta razón, en los próximos apartados hablaremos de las habilidades y los conocimientos que los jóvenes deben adquirir para desarrollar su capacidad de juicio y evaluación. Convenimos con Nussbaum en que lo que parece ser una exigencia irrenunciable es el cultivo de la capacidad crítica, que posibilita un acercamiento a los textos y también al mundo, con aquella «actitud socrática» a la que con tanta frecuencia alude la autora.

\section{Ciudadanía universal, Relativismo y Políticas DE IDENTIDAD}

Nussbaum sostiene que el objetivo de insuflar una conciencia de ciudadanía mundial en los individuos «se opone profundamente al espíritu de fomento de la identidad grupal, según la cual la afiliación primaria de alguien es hacia el propio grupo local» ${ }^{12}$. y denuncia que la oferta académica actual se basa precisamente en dichas políticas de identidad: «bajo el distintivo de "multiculturalismo" - que puede hacer referencia al adecuado reconocimiento de la diversidad humana y la complejidad cultural — ha surgido algunas veces una nueva visión antihumanista, una que alaba la diferencia de un modo poco crítico y que niega toda posibilidad de intereses y entendimiento comunes ${ }^{13}$. La autora propone un ejemplo literario para mostrar dos lectoras opuestas de una misma obra.

Desde la óptica de las políticas de identidad, El hombre invisible de Ellison negará la posibilidad de comprensión, o de tener una experiencia compartida, a todo aquél que no sea afroamericano. Nussbaum, por el contrario, afirma que una persona no tiene por qué pertenecer a un grupo que ha sido tradicionalmente oprimido para comprender las vivencias que un individuo trata de transmitir a través de la escritura. Si las cosas fueran así, la experiencia de las heroínas trágicas sería incomprensible para el hombre contemporáneo, y una novela que tuviera como protagonista a un esclavo negro sería incomprensible para un europeo blanco de nuestros días. Desde una perspectiva universalista, se considerará que la obra contribuye a revelar universales humanos como la búsqueda del sentido de la vida, el sufrimiento relacionado con la pérdida de los seres queridos, o la experiencia del amor. En el caso del ejemplo propuesto por Nussbaum, la lectura invita a que cualquiera se sienta concernido por el problema de la discriminación racial.

Otra cuestión que es preciso atender es que la idea de bien común es una de las ideas de fondo que guía la deliberación pública. De acuerdo con esta

12 Nussbaum, El cultivo de la humanidad. Una defensa clásica de la reforma en la educación liberal, p. 151.

13 Ibid., p. 151. 
concepción, «los ciudadanos aparecen esforzándose por deliberar y por entender más allá de las divisiones» ${ }^{14}$, y comprenden que hay metas comunes que podemos alcanzar mediante la cooperación. La perspectiva identitaria, por el contrario, aborda la deliberación política de una forma muy distinta, describiendo el cuerpo de los ciudadanos «como un mercado de grupos de interés basados en la identidad, que compiten por el poder» ${ }^{15}$. Según la autora, esta concepción mercantilista de la democracia se debe en gran parte a las concepciones reduccionistas de la racionalidad económica, que no hacen sino debilitar la cultura política. Por otra parte, esta visión de las políticas de identidad hace de las diferencias algo que debe afirmarse, en vez de algo que debe comprenderse. Se adopta así una actitud beligerante, que reviste su causa de una estética combativa, y que siempre busca unos Otros (teóricamente muy diferentes) a partir de los cuales definir la propia esencia.

Desde esta perspectiva, además, parece que se renuncia a la idea de deliberación racional, puesto que los grupos de interés, ni tienen intención de entenderse (cada uno busca su autoafirmación, aun si esto va en detrimento de una utilidad que beneficia a todos, incluyéndolos a ellos), ni pueden hacerlo (ya que, supuestamente, son tan diferentes entre sí, y sus objetivos difieren tanto, que sería imposible pensar en un proyecto común). Convendrá por tanto, estar prevenidos ante los excesos de este tipo de políticas y de las derivas perniciosas que puedan imprimir en la educación.

\section{LAS ARTES Y LAS HUMANIDADES EN LA FORMACIÓN DE UNA CIUDADANÍA DEMOCRÁTICA}

Uno de los principales problemas que preocupa a Nussbaum es la deriva actual que está siguiendo la educación. Ésta, sometida a los imperativos del crecimiento económico, está viendo cada vez más marginadas las artes y las humanidades en sus programas de estudios. Nuestra autora, que en sus trabajos sobre el desarrollo humano ya se ocupó de desmentir la falacia que asocia el crecimiento económico con el aumento de la calidad de la vida, considera también que las artes y las humanidades conforman los cimientos de un buena ciudadanía, puesto que son imprescindibles para desarrollar la inteligencia y la capacidad crítica, el pensamiento autónomo, y los medios para poner en cuestión las tradiciones irracionales o la presión de los pares ${ }^{16}$.

Estos cambios en los planes de estudios vienen impulsados principalmente por los Estados, que, obsesionados con la productividad y el crecimiento económico, están relegando a un plano secundario ciertas disciplinas que sirven para formar y fortalecer algunas de las aptitudes que son necesarias para

\footnotetext{
$14 \quad$ Ibid., p. 151.

15 Ibid., p. 151.

16 La obra donde la autora examina más extensamente estas cuestiones es Sin fines de lucro. Por qué la democracia necesita de las humanidades, Katz, Buenos Aires, 2010.
} 
mantener la buena salud de la democracia. Asistimos a una época en la que los recortes, y en especial los recortes de aquellas cosas que supuestamente resultan inútiles o improductivas, la mutilación de las materias relacionadas con las artes y las humanidades es presentada por los gobiernos como una medida en pos de la competitividad.

Pero los gobiernos no son los únicos responsables de la remisión de estas áreas de estudio en los centros de enseñanza, sino que los padres también han participado activamente en su descrédito. La mayor parte de los progenitores consideran que el objetivo de la educación no es otro que conseguir un empleo bien remunerado. La idea de que sus hijos serán algún día no sólo trabajadores, sino también ciudadanos, miembros de una comunidad política y de convivencia, en la que se deberán tomar decisiones que afecten tanto a otros como a ellos mismos, les resulta totalmente ajena. También los jóvenes que empiezan sus estudios universitarios prefieren las carreras denominadas "con futuro», es decir, con buenas posibilidades de empleo y promoción, a las carreras humanísticas, cuya «utilidad» (siempre se utiliza este término) son incapaces de comprender, puesto que ellos mismos conciben su formación no como algo integral, que les ayude a comprender sus propias experiencias internas, sus relaciones con los demás y otras cuestiones de indudable interés (la libertad humana, cómo somos capaces de entender el mundo y de representárnoslo, la diferencia entre hechos e interpretaciones, el miedo ante la muerte, la distinción entre lo descriptivo y lo normativo, etc.), sino como una herramienta para triunfar en el mercado laboral.

Como asimismo señala Nussbaum, también en el ámbito académico se ha dejado de lado la Universidad concebida como lugar de transmisión de conocimiento y cultivo del saber, y se ha pasado a una concepción centrada en la producción y la rentabilidad.

Nuestra autora insiste, por tanto, en que el crecimiento económico por sí mismo no traerá consigo una disminución de las desigualdades sociales, mejoras en la educación, libertades civiles, un progreso en el estado de las relaciones entre razas, o un sistema de salud de calidad para todos los ciudadanos. China constituye un ejemplo de país que ha logrado un asombroso crecimiento económico que deslumbra al resto de naciones, pero que deja mucho que desear respecto del estado de otras cuestiones que tienen que ver con la calidad de la vida de sus habitantes. También es un ejemplo claro de que la productividad y la competitividad no se traducen en un florecimiento de la democracia. Como también hemos visto, por oposición a las perspectivas que ponen el crecimiento económico como medidor de la prosperidad de un país, Nussbaum, junto al economista Amartya Sen, propone un modelo alternativo para medir la calidad de la vida, el «paradigma del desarrollo humano», según el cual:

Lo que importa son las oportunidades o «capacidades» que posee cada persona en ciertas esferas centrales que abarcan desde a vida, la salud y la integridad física hasta la libertad política, la participación política y la 
educación. Este modelo de desarrollo reconoce que todas las personas gozan de una dignidad humana inalienable y que ésta debe ser respetada por las leyes y las instituciones ${ }^{17}$.

La autora insiste en que dos de las cuestiones clave que se deben abordar para lograr sociedades verdaderamente democráticas son la redistribución y la igualdad de oportunidades.

Ahora bien, un ciudadano difícilmente podrá identificar de qué problemas adolece la sociedad a la que pertenece y cuáles pueden ser las posibles soluciones, ni tampoco adquirir un interés por las dos cuestiones clave referidas, si no sabe nada acerca del modo en que las diferencias de clase o de otro tipo afectan a las oportunidades de las personas; sobre las diferencias que hay entre la vida urbana y la vida rural, o la vida en países del primer mundo y países en vías de desarrollo; sobre cómo las oportunidades vitales vienen determinadas en gran medida por la organización política; sobre qué tipos de organización política existen, y qué ventajas e inconvenientes aporta cada una; acerca de cómo los roles de género fijan el papel de los hombres y las mujeres; etc. Como con gran tino señala la propia Nussbaum: «aunque el conocimiento no garantiza la buena conducta, la ignorancia es casi una garantía de lo contrario» ${ }^{18}$.

Una sociedad que quiera mantener la buena salud de la democracia y promover la igualdad de oportunidades para todos sus miembros, deberá fomentar un conjunto de aptitudes en la ciudadanía ${ }^{19}$ :

1) La aptitud para reflexionar sobre las cuestiones políticas que afectan a la nación, analizarlas, examinarlas, argumentarlas y debatirlas.

2) La aptitud de reconocer a los otros ciudadanos como personas con los mismos derechos que uno, aunque sean de distinta raza, religión o sexo y de contemplarlos con respeto, como fines en sí mismos y no como medios para obtener beneficios propios mediante su manipulación.

3) La aptitud para interesarse por la vida de los otros, y de entender las consecuencias que cada política implica para las oportunidades y las experiencias de los demás ciudadanos y de las personas que viven en otras naciones.

4) La aptitud para imaginar una variedad de cuestiones complejas que afectan la trama de una vida humana en su desarrollo y de reflexionar

17 Nussbaum, M., Sin fines de lucro. Por qué la democracia necesita de las humanidades (Katz, Buenos Aires, 2010). p. 47. Sobre el enfoque de las capacidades ver: NusBaum, M. y SEN, A. (comps.), La Calidad de vida, Fondo de Cultura Económica, México, 1998; Las mujeres y el desarrollo humano: el enfoque de las capacidades, Herder, Barcelona, 2002; Crear capacidades, Paidós, Barcelona, 2012. Ver, asimismo: Cortina, A. y Pereira, G. (eds.), Pobreza y libertad. Erradicar la pobreza desde el enfoque de Amartya Sen, Tecnos, Madrid, 2009 y ConiLL, J., Horizontes de economía ética: Aristóteles, Adam Smith, Amartya Sen, Tecnos, Madrid, 2004.

18 Nussbaum, Sin fines de lucro. Por qué la democracia necesita de las humanidades, p. 115 .

19 Ibid., p. 48-49. 
sobre la infancia, la adolescencia, las relaciones familiares, la enfermedad, la muerte y muchos otros temas, fundándose en el conocimiento de todo un abanico de historias concebidas como más que un simple conjunto de datos.

5) La aptitud para emitir un juicio crítico sobre los dirigentes políticos, pero con una idea realista y fundada de las posibilidades concretas que éstos tienen a su alcance.

6) La aptitud para pensar en el bien común de la nación como un todo, no como un grupo reducido a los propios vínculos locales.

7) La aptitud de concebir a la propia nación como parte de un orden mundial complejo en el que distintos tipos de cuestiones requieren de una deliberación transnacional inteligente para su solución.

Pero todas estas aptitudes no se pueden desarrollar si uno no conoce la historia de los países, la historia del trabajo, la historia del pensamiento, la historia de las religiones o la historia del arte. Tampoco sin las habilidades de análisis crítico, de síntesis, de abstracción y de razonamiento, propias de la filosofía, y tan necesarias para abandonar la repetición de tópicos irreflexivos y estereotipos y aprender a pensar por uno mismo, apoyándose en las ideas que otras mentes más brillantes han formulado. Saber leer y escribir bien en la propia lengua tampoco es un asunto baladí, aunque a menudo no se le preste la menor atención. Y también nos beneficiaremos, por supuesto, del conocimiento de otras lenguas.

Asimismo, será preciso que los ciudadanos desarrollen la capacidad discursiva de ponerse en el lugar del otro, de tratar de comprender su punto de vista. Cuanto más completa sea formación de uno en cuanto a la comprensión de las desigualdades, el conocimiento de las diferencias entre clases sociales, o entre sexos, por poner sólo algunos ejemplos, mejor pertrechado se encontrará para entender al otro como un ser merecedor de respeto, por lo demás con una serie de aspiraciones, expectativas y problemas muy parecidos a los propios.

De forma similar, el conocimiento del medio social es preciso para comprender que el bien de todos los seres humanos se encuentra interconectado, ya que, en un mundo cada vez más globalizado, las decisiones que se toman en una parte del mundo afectan irremediablemente a los ciudadanos que se encuentran al otro lado del globo.

Por último, la capacidad para dar un sentido a la propia existencia y para conocerse a uno mismo, y los placeres que se derivan de este tipo de conocimientos no son una cuestión menor, por más que en los planes de estudios rara vez se muestre una preocupación por ellas. Con toda probabilidad, podríamos ahorrarnos grandes dosis de infelicidad y de descontento con la vida (y las consecuencias sociales que de ello se derivan) si la meta de la educación fuera formar a las personas para que tuvieran una inteligencia rica (y no sólo orientada a la adquisición de riqueza) y la capacidad de ser autónomas, en vez de meros productores de objetos (eficaces y competitivos, eso sí), piezas de un engranaje cuya actividad no puede dotar de sentido a sus vidas. 
Nuestra autora insiste en que también es importante tener en cuenta la forma en que estas materias son transmitidas a los alumnos. Nussbaum invoca aquí las ideas del gran pedagogo y filósofo John Dewey, que defendió que un programa de estudios adecuado debería tener en cuenta más dimensiones de la historia que la historia de las vicisitudes militares y políticas. Por el contrario, «la historia económica es más humana, más democrática y por tanto más liberalizadora que la historia política. No trata de la elevación y caída de los príncipes y los potentados, sino del desarrollo de las libertades efectivas (...) » De forma similar, es importante comprender la economía global no sólo en términos económicos, sino también en términos humanos. Nussbaum señala la importancia de que los alumnos comprendan cuál es el origen de los productos que compran. Para ello es preciso recurrir a una historia del trabajo, recrear el modo en que la nación ha ido construyendo su economía, su mercado laboral y las oportunidades para las personas que se derivan de ello, creando así conciencia de las distintas condiciones de vida que se encuentran detrás de cada bien consumido.

\section{Sobre La EdUCACión de LAS EMOCIONES}

En el apartado anterior hemos enumerado un conjunto de aptitudes que es necesario que las personas desarrollen para que puedan hacer un ejercicio plenamente informado y responsable de su ciudadanía. Ahora bien, es preciso averiguar por qué en ocasiones resulta tan difícil que los miembros de una sociedad se comprometan con este tipo de actitudes de respeto e interés mutuo y no se comporten, por el contrario, con animadversión hacia otras personas y grupos sociales distintos de ellos mismos. Las emociones poseen una importancia capital a la hora de explicar estas conductas. Admitiendo que en ellas hay un potencial humanizador enormemente valioso para la vida moral y política, también hay que estar muy atentos a las inclinaciones perversas que en ocasiones se encuentran vinculadas a emociones como la vergüenza o la repugnancia, así como al papel que desempeñan las instituciones a la hora de administrar las economías emocionales de las sociedades.

Los repertorios emocionales se empiezan a adquirir a una edad muy temprana. En la primera infancia aparecen el amor y el odio, la vergüenza originaria y la envidia, la culpa y la voluntad de reparación del mal. También aparece, algo más tarde, la repugnancia, mezcla de reacción fisiológica e imaginación, relacionada con las ideas de contaminación e impureza, que posteriormente puede proyectarse sobre personas o grupos estigmatizados ${ }^{21}$.

20 Dewey, J., Democracy and Education. Dover, Nueva York, 2004. p. 207. Citado en Ibíd., p. 120.

21 Nussbaum analiza ampliamente estas cuestiones en Paisajes del pensamiento: la inteligencia de las emociones, Paidós, Barcelona, 2008, particularmente en el capítulo IV. 
La repugnancia, pero también el resto de emociones, son «un poderoso vehículo de enseñanza social ${ }^{22}$. A través de cada emoción se transmiten un conjunto de actitudes hacia diversas cuestiones. Por ejemplo, a través de la repugnancia, se aprenden actitudes hacia la condición animal y la mortalidad. Si bien los objetos primarios a los que se dirige la repugnancia son más o menos universales precisamente porque son cosas susceptibles de enfermarnos, otros objetos «se convierten en blanco de repugnancia como resultado de formas altamente variables de educación y tradición social». Mediante este mecanismo, el «nosotros», y, en última instancia el "yo» procuran mantenerse alejados de la contaminación y la impureza que es inherente a los objetos señalados como repugnantes. Como señala Nussbaum, los juegos del tipo «caza-piojos» constituyen las primeras tentativas de llevar a cabo estas separaciones. Mediante este juego, que suele aparecer alrededor de los siete u ocho años, los niños simulan que cazan alimañas o piojos de la cabeza de otros niños, generalmente aquellos por los que sienten antipatía, o son más débiles, o son vistos como ajenos al grupo dominante. El juego constituye una «forma de subordinación basada en la repugnancia, conocida en todas las sociedades, y de ese modo dan origen a grupos de humanos que supuestamente tienen las propiedades repugnantes de suciedad, mal olor, contaminación». ${ }^{23}$ Los niños aprenden de esta forma a establecer desigualdades y jerarquías marginando a algunos de sus compañeros y elevándose por encima de ellos mediante su estigmatización.

Otra de las fuerzas que tiran en dirección opuesta a la capacidad de pensamiento autónomo y a la disposición a interesarnos por la vida de los demás es la obediencia a la autoridad. Nussbaum cita los famosos experimentos de Stanley Milgram para explicar este mecanismo psicológico. En estos experimentos, Milgram mostró cómo las personas podemos llegar a hacer a otros cosas que consideramos horribles, simplemente si nos pide que lo hagamos alguien a quien otorgamos cierta autoridad, como un científico con bata blanca. Y actuamos de esta manera incluso si ejecutamos la orden con remordimientos por hacer sufrir a otro ser humano ${ }^{24}$. De forma similar, Solomon Asch, mostró que la presión de nuestros pares también puede deformar nuestro juicio. Estamos dispuestos a decir que vemos una cosa del modo en que los demás dicen que la ven, aun si en realidad no la vemos así. Nadar a contracorriente resulta demasiado duro, y, con frecuencia, sucumbimos con suma facilidad ante la presión de los pares, ya que buscamos la aprobación de los mismos.

Una tendencia humana bastante ubicua, y que está relacionada con las dos anteriores, es la de sumarse a la humillación y la estigmatización de los que son considerados distintos, o anómalos, por el mero placer (si es que se le puede

22 Nussbaum, M., El ocultamiento de lo humano. Repugnancia, vergüenza y ley (Katz, Buenos Aires, 2006), p. 118. Las citas que siguen son de la misma página.

23 Ibid., p. 119.

24 Ver: Asch, S., «Studies of independence and conformity: a minority of one against an unanimous majority», Psychological Monographs 70, n. 9, 1956, p. 1-70 y Milgram, S., Obedience to Authority: an Experimental View, Harper and Collins, Nueva York, 2004. 
llamar así) de dominar y someter, y en particular de hacerlo con los que se encuentran más indefensos. Existen innumerables ejemplos de esta tendencia cuyos indicios, además, comienzan a atisbarse a una edad muy temprana (como ya hemos visto que ocurre en el caso de la repugnancia). Nussbaum ejemplifica estas inclinaciones precoces con un estudio realizado en un aula con niños. En este estudio, Jane Elliot, una profesora de primaria, persuadió a sus alumnos de que los niños de ojos azules eran mejores que los niños de ojos marrones. Pronto, los pequeños que creían ser mejores, comenzaron a obtener mejores resultados académicos, y a tener un comportamiento desdeñoso y altivo hacia sus compañeros menos agraciados. Algún tiempo después, la profesora informó a sus alumnos de que se había equivocado: los niños de ojos marrones eran en realidad más inteligentes que los de ojos azules. ¿Qué ocurrió entonces? Pues que los pequeños de ojos marrones se comportaron exactamente de la misma forma en la que los del otro grupo se habían comportado con ellos. Es decir, que el sufrimiento y la marginación que ellos habían padecido no les sirvieron, por sí solos, para ser más compasivos o benévolos ${ }^{25}$. En los experimentos de la prisión de Stanford dirigidos por Philip Zimbardo parecemos encontrar un mecanismo psicológico muy similar al de los niños: los participantes que desempeñaban el rol de vigilantes, tampoco tardaron en maltratar y humillar a los que representaban el rol de prisioneros ${ }^{26}$.

En definitiva, emociones como la vergüenza y la repugnancia parecen tener un rol fundamental a la hora de establecer jerarquías de incluidos y excluidos,

25 Hubiera sido bueno poder comprobar qué hubiera ocurrido si, con la inversión de roles, se hubiera hecho reflexionar a los niños de ojos marrones sobre su situación precedente, de tal modo que se hubiera aprovechado el material emocional previo (relacionado con el sufrimiento, la tristeza, la vergüenza, etc.) para que los niños comprendieran por qué es malo que los demás sean crueles con uno. Esto quizá hubiera servido para orientar tanto las disposiciones emocionales como las acciones que estaban por venir. Es preciso señalar que la intención de la profesora era que los niños tuvieran experiencia en carne propia de lo que era la discriminación para que no repitieran esos comportamientos, cosa que, a juzgar por las opiniones expresadas por los participantes años después, consiguió con éxito. El vídeo del estudio, así como una batería de entrevistas posteriores pueden encontrarse en: http://www. pbs.org/wgbh/pages/frontline/shows/divided/etc/view.html.

26 Zimbardo habla de estos experimentos en Lucifer Effect: Understanding how Good People Turn Evil (Random House, Nueva York, 2008. Tanto los experimentos de Zimbardo como el resto de los estudios mencionados recuerdan de forma inevitable la «banalidad del mal» postulada por Arendt, según la cual los motivos y el carácter que llevan a hacer el mal no son monstruosos, sino banales. Los especialistas que tuvieron que realizar un informe psicológico para el juicio contra Eichmann, lo describieron como una persona normal, no como a un monstruo o un enfermo. Él mismo afirmó que no era un canalla, sino alguien que cumplía órdenes de forma diligente y meticulosa. Y esto planteó, al parecer de Arendt, la mayor dificultad moral y jurídica para los jueces, que zanjaron la cuestión asumiendo que el acusado era un embustero. Arendt concluye que sus acciones derivaron de la falta absoluta de pensamiento (la filósofa distinguió claramente la falta de pensamiento de la estupidez, insistiendo en que no era esto último a lo que ella se refería). En el capítulo segundo de Hannah ARENDT, Eichmann en Jerusalén, Lumen, Barcelona, 2003, encontramos una reflexión sobre estas cuestiones. 
de privilegiados y marginados, de denigradores y humillados. Mediante el recurso a alguna de estas emociones, el otro es representado como un ser repulsivo, aberrante y vil. De lo que se trata es de despojar a ese otro de todo indicio de humanidad, para establecer una frontera bien delimitada entre los que son como él, ellos, y nosotros. Una persona que no ha recibido una adecuada formación ciudadana, será propensa a buscar un chivo expiatorio sobre el que descargar la rabia y la indignación por los problemas. Dado que la comprensión del mundo se le escapa, este mal llamado ciudadano busca una explicación fácil con la que satisfacer la necesidad de entender y de posicionarse ante una cuestión de interés público.

Pero no todo son malas noticias. Los niños tienen inclinaciones con una carga moral positiva desde sus primeros meses de vida, tanto mecanismos empáticos que provocan automáticamente su llanto ante el llanto de otros bebés, como unas ideas rudimentarias de justicia y reparación que aparecen tan pronto como el pequeño comprende que está mal hacer daño a las personas que quiere ${ }^{27}$. Las emociones, por tanto, no son ni buenas ni malas en sí mismas, sino que terminarán siendo una cosa u otra en función de la forma que tomen. Como ya hemos indicado al principio de este apartado, las emociones son un eficaz vehículo de enseñanza desde las que se transmiten a los niños ideas acerca de lo temible, lo odioso, lo repugnante, lo digno de ser amado o compadecido.

En línea con este razonamiento, Nussbaum señala que no es apropiado creer que las emociones son impulsos irracionales que, o bien reprimimos por la fuerza, o bien nos arrastran. Por el contrario, "pensamos que es posible razonar al respecto: que las personas cambiarán una vez se deshagan de —o, mucho mejor, nunca adquieran- las creencias equivocadas respecto de cuestiones de hecho y valoración que forman la base de estos odios ${ }^{28}$.

Precisamente a causa del vínculo que existe entre creencias y emociones, nuestra autora insiste reiteradamente en la importancia de sostener una concepción cognitiva de las emociones. De nuevo, Nussbaum tiene una voluntad práctica: mostrarnos no sólo que es posible, sino también que es necesario, hacernos responsables de nuestras emociones, tanto en la esfera de la conducta

27 En Decety, J. y Svetlovab, M., «Putting together phylogenetic and ontogenetic perspectives on empathy», Developmental cognitive neuroscience 2, $\mathrm{n}^{\circ} .1$ (2012), pp. 1-24 se puede encontrar un resumen del desarrollo de la empatía desde las meras formas de contagio emocional de los bebés hasta llegar a otras formas más complejas de comportamiento empático que se dan ya en la edad adulta.

28 Nussbaum, El ocultamiento de lo humano. Repugnancia, vergüenza y ley, p. 50. Sobre la idea de ser responsables de nuestras emociones, ver: SHERMAN, N., «Taking responsibility for our emotions», Social Philosophy and Policy 16, n. 2, 1999, p. 294-328; SHERMAN, N., "Of manners and morals», British Journal of Educational Studies 55, nº. 3, 2005, p. 272-89; RoBERTs, R. C., "Solomon on the control of emotions», Philosophy and Phenomenological Research 44, $\mathrm{n}^{\circ} .3$, 1984, p. 395-403 y Neu, J., "Emotions and freedom», in Thinking about Feeling. Contemporary Philosophers on Emotions, ed. Robert Solomon (Oxford University Press, Oxford, 2004), pp. 163-82. 
individual, como en lo que refiere a su dimensión pública. De este modo, actitudes tales como el racismo o el desprecio por algunos grupos sociales (como los discapacitados), así como las emociones relacionadas con estas actitudes, no serían defendibles sobre la base de un supuesto naturalismo, sino que serían formas de comportamiento susceptibles de ser instigadas o suprimidas a través de los procesos de socialización y aprendizaje, que inculcan creencias y formas de valorar los hechos del mundo.

Pero Nussbaum no sostiene una postura ingenua o irrazonable respecto a las posibilidades de educación (o reeducación) de las emociones. Antes bien, la autora afirma que «el esfuerzo por tener emociones apropiadas es una batalla cuesta arriba (...) para todos los seres humanos», y añade que en ningún caso tenemos garantías de que este proceso vaya a resultar exitoso, puesto que la mayoría de las personas carece de la determinación, la formación o la paciencia para dedicarse a ello de forma constante ${ }^{29}$.

Las emociones nos hablan de nuestro excepcional lugar entre naturaleza y cultura, y también de nuestra capacidad para adaptar las fuerzas biológicas a las normas sociales y morales. Por esta razón, el estudio de las emociones debe abordarse desde distintos frentes: desde las ciencias empíricas y desde las humanidades. La neurociencia, la biología, y las disciplinas que investigan con una metodología empírica proporcionan datos objetivos y, en consecuencia, su aportación es muy valiosa. Pero no por ello hay que desdeñar las contribuciones de las humanidades, cuya misión no es la investigación empírica, sino la reflexión, igualmente necesaria. Como señala Adela Cortina con gran acierto, junto a las bases cerebrales, también existen otras bases que deben ser estudiadas a la hora de analizar nuestra conducta. Factores sociológicos, educativos, económicos, históricos y demás elementos coyunturales deben ser tenidos en cuenta para comprender la agencia humana ${ }^{30}$.

Pero, además, ocurre que el hecho de ofrecer una explicación empírica de la conducta no es suficiente, ya que estas disciplinas nos sirven para describir la realidad y también para explicarla (aunque sea de forma imperfecta), pero no pueden decirnos "por qué debemos» actuar de un modo u otro, cómo podemos ser mejores o qué es digno de ser considerado valioso. Para ello es preciso recurrir a la reflexión filosófica. Por estas razones, recurrir a la psicología, las neurociencias, la sociología u otras áreas de estudio empíricas nos puede servir para comprender las emociones, pero no para orientar nuestra acción. La tarea de la filosofía consiste en complementar estos conocimientos, prestando atención a los aspectos normativos: pensar por qué unas emociones son más apropiadas que otras, por qué algunas apoyan y otras subvierten los principios democráticos sobre los que debe asentarse una sociedad justa, o qué objetos son apropiados para las emociones y cuáles no.

29 Nussbaum, El ocultamiento de lo humano. Repugnancia, vergüenza y ley, p. 50-51.

30 Cortina, A., Neuroética y Neuropolítica: Sugerencias para la educación moral, Tecnos, Madrid, 2011, p. 94-96. 


\section{BibliografíA}

Arendt, H., Eichmann en Jerusalén. Barcelona: Lumen, 2003.

Arteta, A., La compasión, apología de una virtud bajo sospecha. Barcelona: Paidós, 1996. $\mathrm{AscH}, \mathrm{S}$., «Studies of independence and conformity: a minority of one against an unanimous majority». Psychological Monographs 70, n. 9 (1956): 1-70.

Conill, J., Horizontes de economía ética: Aristóteles, Adam Smith, Amartya Sen. Madrid: Tecnos, 2004.

Cortina, A., Neuroética y Neuropolítica: sugerencias para la educación moral. Madrid: Tecnos, 2011.

- Justicia cordial. Madrid: Trotta, 2010.

- Ética de la razón cordial: educar en la ciudadanía en el siglo XXI. Oviedo: Nobel, 2007.

Cortina, A. y Pereira, G. (eds.), Pobreza y libertad. Erradicar la pobreza desde el enfoque de Amartya Sen, Tecnos: Madrid, 2009.

DE Beauvoir, S., El segundo sexo. Madrid: Cátedra, 2005.

Decety, J. y Svetlovab, M., «Putting together phylogenetic and ontogenetic perspectives on empathy», Developmental cognitive neuroscience 2, n. 1 (2012): 1-24.

Dewey, J., Democracy and Education. Nueva York: Dover, 2004.

KidD, D. y Castano, E., «Reading literary fiction improves theory of mind». Science 342, $\mathrm{n}^{\mathrm{o}} .6156$ (2013): 377-80.

MèLich, J. C., Ética de la compasión. Barcelona: Herder, 2010.

Milgram, S., Obedience to authority: an experimental view. Nueva York: Harper and Collins, 2004.

Neu, J., «Emotions and freedom». En Thinking about feeling. Contemporary philosophers on emotions, Robert Solomon (ed.), 163-82. Oxford: Oxford University Press, 2004.

Nussbaum, M., Crear capacidades. Barcelona: Paidós, 2012.

- Sin fines de lucro. Por qué la democracia necesita de las humanidades. Buenos Aires: Katz, 2010.

- Paisajes del pensamiento: la inteligencia de las emociones. Barcelona: Paidós, 2008

- El ocultamiento de lo humano. Repugnancia, vergüenza y ley. Buenos Aires: Katz, 2006.

- Las mujeres y el desarrollo humano: el enfoque de las capacidades. Barcelona: Herder, 2002;

- El cultivo de la humanidad. Una defensa clásica de la reforma en la educación liberal. Barcelona: Paidós, 2001.

- Justicia poética: la imaginación literaria y la vida pública. Barcelona: Andrés Bello, 1997.

- «Compassion: The basic social emotion». Social Philosophy and Policy 13, $\mathrm{n}^{\circ} .1$, 1996, p. 27-58.

Nusbaum, M. y Sen, A. (comps.), La calidad de vida. México: Fondo de Cultura Económica, 1998.

Rawls, J., El liberalismo político. Barcelona: Crítica, 2004.

Roberts, R. C., «Solomon on the control of emotions». Philosophy and Phenomenological Research 44, nº. 3 (1984): 395-403.

SHERMAN, N., "Of manners and morals». British Journal of Educational Studies 55, n 3 (2005): 272-89.

- «Taking responsibility for our emotions». Social Philosophy and Policy 16, $\mathrm{n}^{\circ} .2$ (1999): 294-323. 
Zimbardo, P., Lucifer effect: understanding how good people turn evil. Nueva York: Random House, 2008.

Universidad de Valencia

Marta Gil Blasco

Marta.Gil@uv.es

[Artículo aprobado para publicación en noviembre de 2014] 